\begin{tabular}{ll|l} 
Case Reports in & \multicolumn{2}{c}{ Case Rep Gastroenterol 2013;7:442-448 } \\
\cline { 2 - 3 } Gastroenterology & $\begin{array}{l}\text { DOI: 10.1159/000355884 } \\
\text { Published online: October 9, 2013 }\end{array}$ & $\begin{array}{l}\text { ○ 2013 S. Karger AG, Basel } \\
\text { www.karger.com/crg }\end{array}$ \\
\hline & $\begin{array}{l}\text { This is an Open Access article licensed under the terms of the Creative Commons } \\
\text { Attribution-NonCommercial 3.0 Unported license (CC BY-NC) (www.karger.com/OA- } \\
\text { license), applicable to the online version of the article only. Distribution permitted for non- } \\
\text { commercial purposes only. }\end{array}$
\end{tabular}
commercial purposes only.

\title{
Repeated Pancreatectomy for Metachronous Duodenal and Pancreatic Metastases of Renal Cell Carcinoma
}

\author{
Tatsuo Hata $^{a}$ Naoaki Sakata ${ }^{a}$ Takeshi Aoki $^{a}$ Hiroshi Yoshida $^{a}$ \\ Atsushi Kanno $^{b}$ Fumiyoshi Fujishima $^{c}$ Fuyuhiko Motoi $^{a}$ \\ Atsushi Masamune $^{b}$ Tooru Shimosegawa $^{b}$ Michiaki Unno $^{a}$ \\ ${ }^{a}$ Division of Hepato-Biliary-Pancreatic Surgery, Department of Surgery, and ${ }^{b}$ Division of \\ Gastroenterology, Tohoku University Graduate School of Medicine, and 'Department of \\ Pathology, Tohoku University Hospital, Sendai, Japan
}

\section{Key Words}

Renal cell carcinoma · Pancreas · Duodenum · Metastasis · Pancreatectomy

\begin{abstract}
A 50-year-old woman had undergone left nephrectomy for renal cell carcinoma 13 years previously. Ten years later, a solitary metastatic tumor had been detected in the pancreatic tail and she had undergone subsequent resection of the pancreatic tail and spleen. Three years after surgery, she was admitted to our hospital for severe anemia resulting from gastrointestinal tract bleeding. Esophagogastroduodenoscopy revealed a 3-cm solid tumor at the oral side of the papilla of Vater. Histology of the bioptic duodenal tissue revealed inflammatory granulation without malignancy. Computed tomography showed a well-contrasted hypervascular tumor in the descending portion of the duodenum. We diagnosed the patient with metachronous duodenal metastasis of renal cell carcinoma and performed a pancreaticoduodenectomy. An ulcerated polypoid mass was detected at the oral side of the papilla of Vater. Histology revealed clear cell carcinoma coated by granulation tissue across the surface of the tumor. Immunohistology demonstrated that the cells were positive for vimentin, CD10 and epithelial membrane antigen and negative for CK7. After a repeated pancreatectomy, the patient had no symptoms of gastrointestinal bleeding and maintained good glucose tolerance without insulin therapy because the remnant pancreas functioned well. In conclusion, for the diagnosis of patients who have previously undergone nephrectomy and present with gastrointestinal bleeding, the possibility of metastasis to the gastroin-
\end{abstract}


Hata et al.: Repeated Pancreatectomy for Metachronous Duodenal and Pancreatic Metastases of Renal Cell Carcinoma

testinal tract, including the duodenum, should be considered. With respect to surgical treatment, the pancreas should be minimally resected to maintain a free surgical margin during the first surgery taking into account further metachronous metastasis to the duodenum and pancreas.

(C) 2013 S. Karger AG, Basel

\section{Introduction}

Renal cell carcinoma (RCC) has the potential to spread to almost all sites, including the lungs, lymph nodes, liver, bones, adrenal glands, kidneys, brain, heart, spleen, intestine and skin [1]. However, only $4 \%$ of RCCs metastasize to the small intestine, and duodenal metastasis occurs less frequently than metastasis to the jejunum and ileum [2]. RCC metastasis to the duodenum is also a rare event, accounting for $7.1 \%$ of all small bowel metastases [3]. Furthermore, approximately one-half of patients who undergo nephrectomy for RCC develop widespread metastases despite the primary RCC being localized [4]. Herein, we present a case of late-onset, metachronous duodenal metastasis of RCC after resection of the pancreatic tail to remove a metastatic tumor. Repeated pancreatectomy for pancreatic and duodenal metastases was the favored surgery because total resection of the remnant pancreas followed by permanent, intensive insulin therapy may not be required.

\section{Case Report}

A 50-year-old woman was referred to our hospital for treatment of a duodenal tumor. She had a 13-year history of left nephrectomy for RCC. The histologic diagnosis was clear cell carcinoma of grade 2, pT2N0M0, and pStage II (according to the current TNM staging of the Union for International Cancer Control, 7th edition). The postoperative course was uneventful, and no adjuvant therapy was administered.

Three years after nephrectomy, the patient underwent external beam radiation therapy (a total of $46 \mathrm{~Gy}$ ) for a solitary metastatic bone tumor in the seventh thoracic vertebra. A further 7 years later, a solitary metastatic tumor was detected in the tail of the pancreas, and resection of the pancreatic tail and spleen was performed. Since the histologic findings of the pancreatic tumor were similar to those of the kidney, metachronous metastasis of RCC to the tail of the pancreas was assumed. A further 3 years after resection of the pancreatic tail, severe anemia was detected during a regular examination. The patient mentioned the presence of persistent tarry stools for 3-4 weeks. Esophagogastroduodenoscopy (EGD) was performed and revealed a mass in the descending portion of the duodenum.

The patient was admitted to our hospital and underwent detailed examinations. Her hemoglobin level was $7.5 \mathrm{~g} / \mathrm{dl}$. A subsequent EGD revealed an ulcerated polypoid mass in the descending portion of the duodenum; the mass was adjacent to the oral side, but did not involve the papilla of Vater (fig. 1a). Endoscopic ultrasonography showed the tumor to be partially invading the head of the pancreas (fig. 1b). Duodenography revealed a protruding lesion at the wall of the pancreatic side of the descending portion of the duodenum (fig. 1c). Abdominal enhanced computed tomography depicted a well-contrasted, hypervascular mass (fig. 1d). Magnifying endoscopy showed a diminished mucosal surface pattern of the gastrointestinal epithelium across the surface of the tumor (fig. 1e). Furthermore, combined with narrow-band imaging (NBI), it also showed a highly dense assembly of microvessels on the surface of the tumor that did not form a capillary network pattern (fig. 1f). A duodenal biopsy was performed, and the histopathologic diagnosis was inflammatory granulation 
Hata et al.: Repeated Pancreatectomy for Metachronous Duodenal and Pancreatic Metastases of Renal Cell Carcinoma

with no malignancy. An additional duodenal biopsy for histologic confirmation was not performed to avoid uncontrollable duodenal bleeding from the biopsy site. Although partial resection of the pancreas had already been performed for a metastatic tumor of the pancreatic tail, the remnant pancreas was of rich volume (fig. 1d). There was no evidence of metastasis to the lung, liver, lymph nodes or other organs. Enterography showed no abnormal findings suggestive of metastasis to the small intestine. Fluorodeoxyglucose (FDG)positron emission tomography showed specific FDG uptake in the duodenal tumor (standardized uptake value [SUV $\left.\mathrm{Sax}_{\max }\right]$ 6.1). No abnormally enhanced lesions were identified in the body. The levels of both carcinoembryonic antigen and carbohydrate antigen 19-9 were within normal ranges. Resultantly, our diagnosis was metachronous, solitary duodenal metastasis derived from RCC, and we therefore performed a pancreaticoduodenectomy.

There were no findings of malignant ascites, carcinomatosis, omental implants or distant metastases to other abdominal organs; we therefore subsequently performed a subtotal, stomach-preserving pancreaticoduodenectomy, choledochojejunostomy, pancreaticojejunostomy, and gastrojejunostomy with preservation of the left gastric artery and vein to maintain the supply and drainage blood flow to the stomach after splenectomy. The pancreas was dissected just above the portal vein. Regional lymph node dissection was minimized.

Macroscopic findings of the resected specimen indicated that the polypoid mass at the descending portion of the duodenum was ulcerative and friable (fig. 2a). Histologic findings revealed that the surface of the tumor was coated by granulation tissue consisting of inflammatory cells, fibrosis and edematous stroma (fig. 2b). Furthermore, the cancerous lesion comprised clear cells containing glycogen that were arranged in an alveolar pattern (fig. 2c). The tumor had invaded the duodenal muscle and partially invaded the pancreas at a depth of $2 \mathrm{~mm}$. Although the tumor was located very close to the lower common bile duct and main pancreatic duct, histologic direct invasion was not observed in either duct. Immunohistology showed that the tumor cells were positive for vimentin and CD10 and negative for CK7 (fig. 2d-f). The histologic diagnosis was metastatic RCC.

The patient experienced postoperative leakage from the gastrojejunostomy. After percutaneous drainage of the intra-abdominal abscess, she recovered and was discharged on postoperative day 59. One year after surgery, the patient maintained a good glucose tolerance and received only oral hypoglycemic agents and no insulin therapy. Furthermore, she had no evidence of re-bleeding or recurrence of RCC.

\section{Discussion}

RCC is characterized by potential recurrence long after nephrectomy. Although the primary RCC is a localized tumor, recurrence occurs in approximately $25-50 \%$ of RCC cases after nephrectomy [4]. McNichols et al. [4] reported that $11 \%$ of patients who survived 10 years after nephrectomy experience late recurrence. Rustagi et al. [5] revealed that the mean postnephrectomy duration to the diagnosis of duodenal metastases was 7.9 years. Therefore, the possibility of late-onset recurrence and the necessity of long-term follow-up examinations after nephrectomy should be considered. Most patients (69\%) with duodenal metastases had a history of gastrointestinal bleeding [5]. Furthermore, duodenal metastases are most frequently located in periampullary lesions, followed by the duodenal bulbs [6]. For these reasons, EGD is an essential examination for patients with RCC who have undergone nephrectomy, even after a long postoperative period. 
Hata et al.: Repeated Pancreatectomy for Metachronous Duodenal and Pancreatic Metastases of Renal Cell Carcinoma

One of the specific features of the detailed preoperative examinations was that we could not identify any surface pattern or capillary network on the surface of the duodenal tumor based on magnifying endoscopy with NBI. Magnifying endoscopy with NBI often reveals the minute structure of the mucosa in a cancerous lesion, identifying various changes of increased intensity, heterogeneous distribution and avascular areas of microvessels, depending on the degree of metaplastic and dysplastic changes on the surface of a gastrointestinal tumor $[7,8]$. In our case, only dense microvessels without a specific capillary network were observed on the entire surface of the tumor. In combination with the histologic findings, these endoscopic findings may reflect granulation. Among previous reported cases of duodenal metastasis derived from RCC, several reports demonstrated difficulties assessing the histopathology of biopsies and tumors with macroscopic ulcerative changes and microscopic granulomatous inflammation [9-11]. In this case, it was speculated that the severe anemia caused by the metastatic tumor with hypervascularity led to a decreased oxygenized blood supply to the tumor itself. Therefore, local hypoxia in the tumor caused tissue necrosis and the subsequent formation of granulation as tissue healing. The clinical significance and usefulness of magnifying endoscopy with NBI for the diagnosis of tumors coated by granulation tissue, such as RCC metastases, should be discussed.

With respect to treatment, the National Comprehensive Cancer Network (NCCN) guidelines for kidney cancer recommend resection for solitary metastatic tumors (whether synchronous or metachronous) in addition to primary RCC [12]. Surgical resection of solitary metastatic RCC has resulted in 5-year survival rates of 35-50\% [13, 14]. The conventional surgical treatment for metastasis in the head of the pancreas is pancreaticoduodenectomy. However, in some cases, partial resection of the duodenum, transarterial catheter embolization or radiation therapy are performed as less invasive treatments to avoid burden to the patients $[9,15]$. Treatment for metastatic RCC should be individually tailored, with consideration of the patient's general condition and metastases at other sites. In this case, the metastatic tumor had directly invaded the pancreatic head, and the patient was in good condition with no comorbidity. We therefore performed pancreaticoduodenectomy. Fortunately, the tail of the pancreas had been minimally resected during previous surgery. Consequently, we were able to perform pancreaticoduodenectomy. The patient was administered only oral hypoglycemic agents and maintained a good blood glucose level without insulin therapy. Maintaining a good quality of life is as important for long-term survivors who undergo nephrectomy as for those undergoing complete resection of metastatic tumors derived from RCC.

In conclusion, we present a case of repeated pancreatectomy for metachronous pancreatic and duodenal metastases after nephrectomy for RCC. Given the possibility of repeated metachronous metastases in the region of the duodenum and pancreas and the quality of life of long-term survivors who undergo nephrectomy, careful and long-term observation and minimal resection should be performed with no residual tumor.

\section{Disclosure Statement}

The authors have no competing interests to disclose. 
Hata et al.: Repeated Pancreatectomy for Metachronous Duodenal and Pancreatic Metastases of Renal Cell Carcinoma

\section{References}

Saitoh H: Distant metastasis of renal adenocarcinoma. Cancer 1981;48:1487-1491.

Graham AP: Malignancy of the kidney, survey of 195 cases. J Urol 1947;58:10-21. Brener ZZ, Zhuravenko I, Jacob CE, Bergman M: An unusual presentation of renal cell carcinoma with late metastases to the small intestine, thyroid gland, nose and skull base. Nephrol Dial Transplant 2007;22: 930-932.

-4 McNichols DW, Segura JW, DeWeerd JH: Renal cell carcinoma: long-term survival and late recurrence. J Urol 1981;126:17-23.

-5 Rustagi T, Rangasamy P, Versland M: Duodenal bleeding from metastatic renal cell carcinoma. Case Rep Gastroenterol 2011;5:249-257.

-6 Pavlakis GM, Sakorafas GH, Anagnostopoulos GK: Intestinal metastases from renal cell carcinoma: a rare cause of intestinal obstruction and bleeding. Mt Sinai J Med 2004;71:127-130.

7 Li HY, Ge ZZ, Fujishiro M, Li XB: Current clinical applications of magnifying endoscopy with narrow band imaging in the stomach. Diagn Ther Endosc 2012;2012:271914.

$\checkmark 8$ Hayashi N, Tanaka S, Kanao H, Oka S, Yoshida S, Chayama K: Relationship between narrow-band imaging magnifying observation and pit pattern diagnosis in colorectal tumors. Digestion 2013;87:53-58.

-9 Zhao H, Han K, Li J, Liang P, Zuo G, Zhang Y, Li H: A case of wedge resection of duodenum for massive gastrointestinal bleeding due to duodenal metastasis by renal cell carcinoma. World J Surg Oncol 2012;10: 199.

10 Hashimoto M, Miura Y, Matsuda M, Watanabe G: Concomitant duodenal and pancreatic metastases from renal cell carcinoma: report of a case. Surg Today 2001;31:180-183.

-11 Toh SK, Hale JE: Late presentation of a solitary metastasis of renal cell carcinoma as an obstructive duodenal mass. Postgrad Med J 1996;72:178-179.

12 Motzer RJ, Agarwal N, Beard C, Bolger GB, Boston B, Carducci MA, Choueiri TK, Figlin RA, Fishman M, Hancock SL, Hudes GR, Jonasch E, Kessinger A, Kuzel TM, Lange PH, Levine EG, Margolin KA, Michaelson MD, Olencki T, Pili R, Redman BG, Robertson CN, Schwartz LH, Sheinfeld J, Wang J: NCCN clinical practice guidelines in oncology: kidney cancer. J Natl Compr Canc Netw 2009;7:618-630.

Freed SZ: Nephrectomy for renal cell carcinoma with metastases. Urology 1977;9:613-616.

Tolia BM, Whitmore WF Jr: Solitary metastasis from renal cell carcinoma. J Urol 1975;114:836-838. Lynch-Nyhan A, Fishman EK, Kadir S: Diagnosis and management of massive gastrointestinal bleeding owing to duodenal metastasis from renal cell carcinoma. J Urol 1987;138:611-613. 


\section{Case Reports in \\ Gastroenterology}

\begin{tabular}{l|l}
\hline \multicolumn{2}{l}{ Case Rep Gastroenterol 2013;7:442-448 } \\
\hline DOI: $10.1159 / 000355884$ & $\begin{array}{l}\text { C } 2013 \text { S. Karger AG, Basel } \\
\text { www.karger.com/crg }\end{array}$ \\
\hline
\end{tabular}

Hata et al.: Repeated Pancreatectomy for Metachronous Duodenal and Pancreatic Metastases of Renal Cell Carcinoma
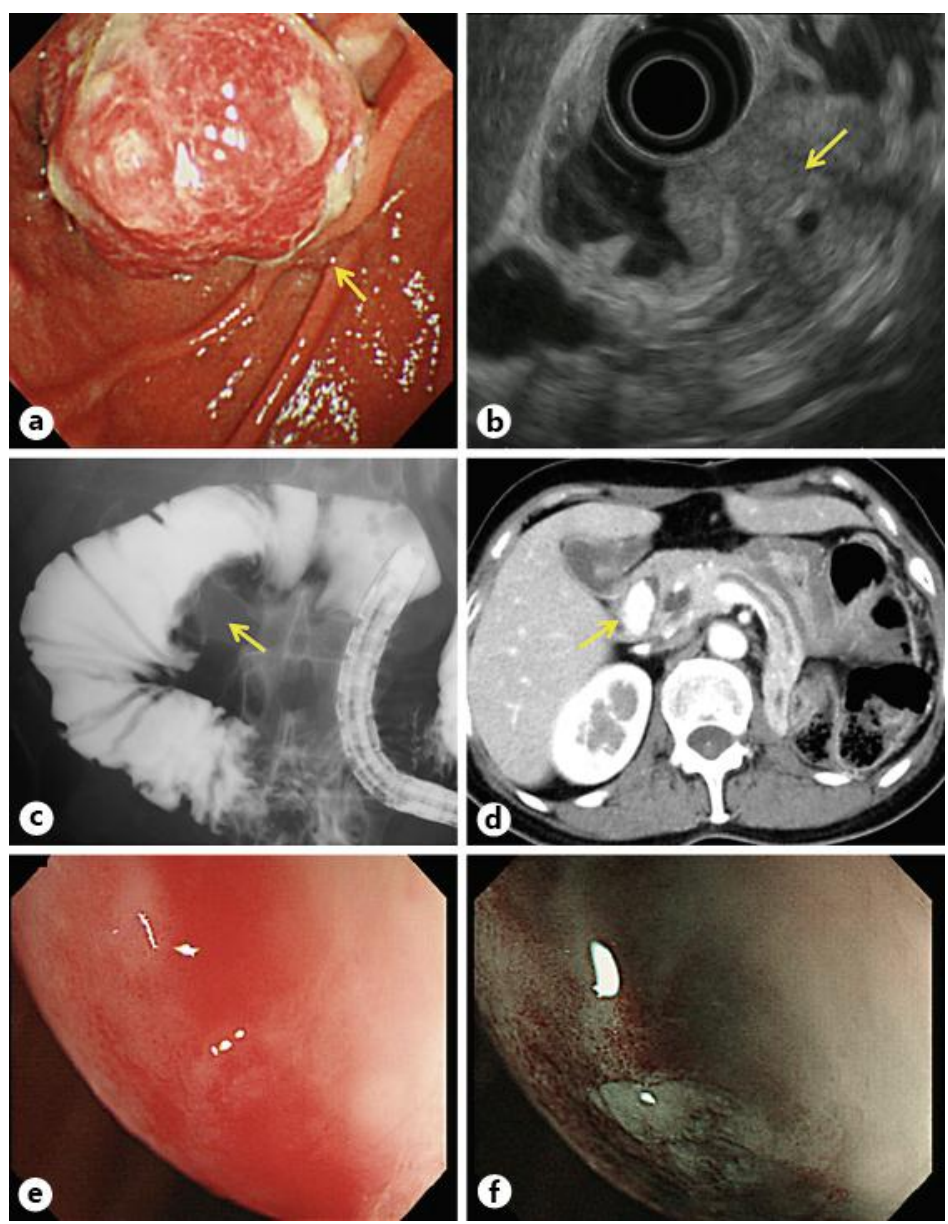

Fig. 1. a Endoscopic image depicting a 3-cm mass in the descending portion of the duodenum that is adjacent to the oral side but does not involve the papilla of Vater. The papilla of Vater is indicated by an arrow. b Endoscopic ultrasonography image showing the tumor partially invading the head of the pancreas (arrow). c Duodenography showing a protruding lesion in the descending portion of the duodenum (arrow). d Computed tomography image showing an ill-defined hypervascular mass (arrow). The tail of the pancreas had been minimally resected during a previous surgery. e Magnifying endoscopy depicting a diminished surface pattern of the gastrointestinal epithelium across the entire surface of the tumor. f Magnifying endoscopy combined with NBI depicting a diminished capillary network pattern. 


\section{Case Reports in \\ Gastroenterology}

\begin{tabular}{l|l}
\hline \multicolumn{2}{l}{ Case Rep Gastroenterol 2013;7:442-448 } \\
\hline DOI: $10.1159 / 000355884$ & $\begin{array}{l}\text { C 2013 S. Karger AG, Basel } \\
\text { www.karger.com/crg }\end{array}$ \\
\hline
\end{tabular}

Hata et al.: Repeated Pancreatectomy for Metachronous Duodenal and Pancreatic Metastases of Renal Cell Carcinoma
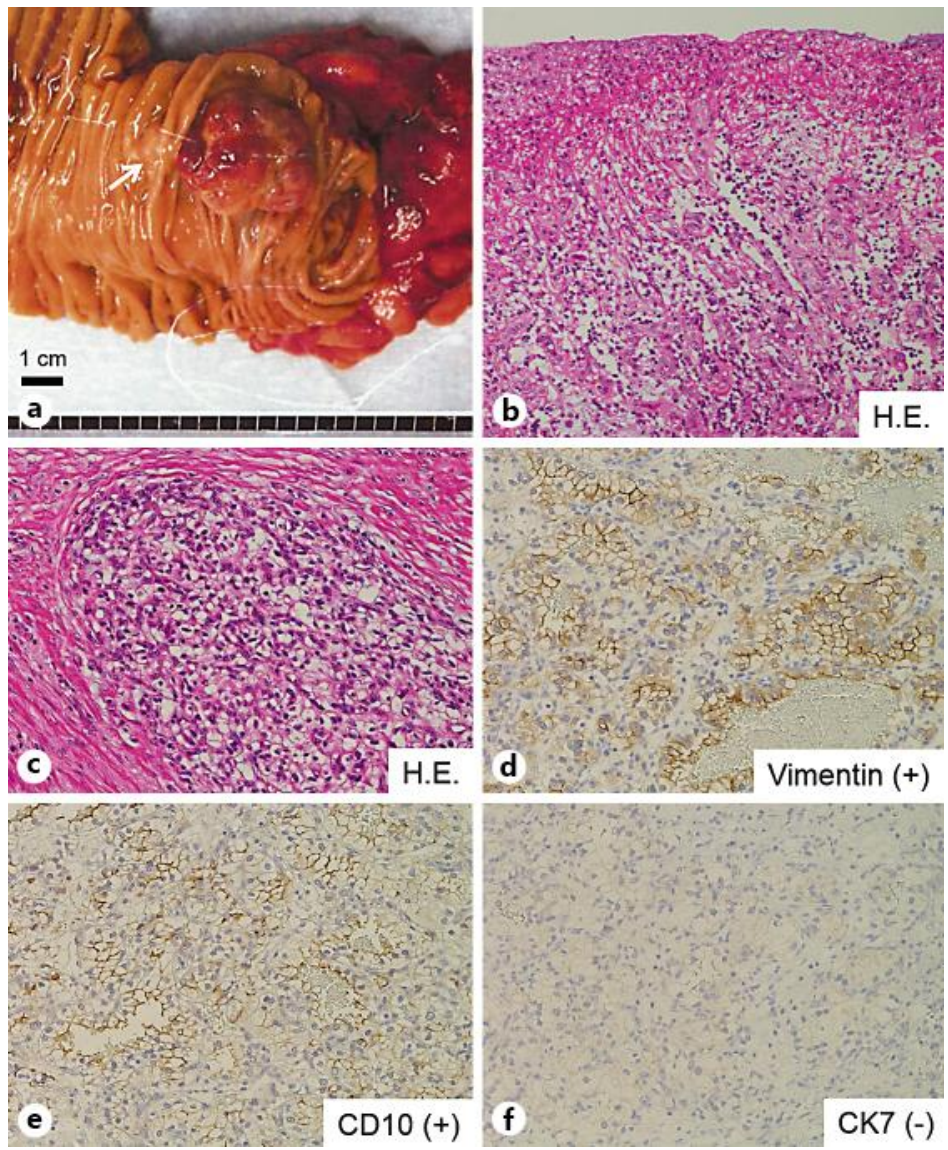

Fig. 2. a Macroscopic findings of the resected specimen reveal a polypoid mass in the descending portion of the duodenum that appears ulcerative and friable. The papilla of Vater is indicated by an arrow. b Histologic findings show that the surface of the tumor was coated by granulation tissue consisting of inflammatory cells, fibrosis and edematous stroma. c Histologic image shows dysplastic clear cells containing glycogen and arranged in an alveolar pattern. d-f Immunohistochemical staining demonstrates that the clear cells are positive for vimentin (d) and CD10 (e) and negative for CK7 (f), confirming the diagnosis of RCC with clear cell histology. 